\title{
Routine Neuroimaging in Patients with Stage IV Non-Small Cell Lung Cancer: A Single Center Experience
}

\author{
Maude Dubé-Pelletier and Catherine Labbé * \\ Institut Universitaire de Cardiologie et de Pneumologie de Québec, Université Laval, \\ Laval, QC G1V 0A6, Canada; maude.dube-pelletier.1@ulaval.ca \\ * Correspondence: catherine.labbe@criucpq.ulaval.ca
}

check for

updates

Citation: Dubé-Pelletier, M.; Labbé, C. Routine Neuroimaging in Patients with Stage IV Non-Small Cell Lung Cancer: A Single Center Experience. Curr. Oncol. 2021, 28, 1125-1136. https://doi.org/10.3390/ curroncol28020108

Received: 8 January 2021

Accepted: 27 February 2021

Published: 2 March 2021

Publisher's Note: MDPI stays neutral with regard to jurisdictional claims in published maps and institutional affiliations.

Copyright: (c) 2021 by the authors. Licensee MDPI, Basel, Switzerland. This article is an open access article distributed under the terms and conditions of the Creative Commons Attribution (CC BY) license (https:// creativecommons.org/licenses/by/ $4.0 /)$.
Abstract: Background: There is a lack of consensus in current practice guidelines regarding routine neuroimaging in patients with stage IV non-small cell lung cancer (NSCLC) without neurologic symptoms, and there is a paucity of data on the impact of such imaging on overall survival (OS). Methods: This retrospective study included 257 patients with stage IV NSCLC without neurologic symptoms diagnosed between January 1, 2013 and December 31, 2016 at Institut universitaire de cardiologie et de pneumologie de Québec (IUCPQ). The primary objective of this study was to compare the evolution of patients with stage IV NSCLC who had baseline brain imaging versus with who did not. Secondary objectives were to determine the proportion of patients who underwent brain imaging in their initial investigation and the proportion of patients who developed metachronous central nervous system (CNS) metastasis. Results: CNS imaging, mainly with computed tomography (CT), was performed at diagnosis in $56 \%$ of patients, and the prevalence of synchronous CNS metastasis among these patients was $32 \%$. There was no difference in median OS between patients who underwent initial CNS imaging and those who did not, but we did show a tendency for a higher cumulative incidence of metachronous CNS metastasis in patients without baseline imaging. These metachronous metastases were symptomatic and were more often not treated when compared to synchronous metastases. Conclusions: In this small, unicentric retrospective study, there was no benefit with routine neuroimaging in terms of median OS in stage IV NSCLC patients without neurologic symptoms.

Keywords: stage IV non-small cell lung cancer; central nervous system metastasis; neuroimaging

\section{Introduction}

Lung cancer, specifically non-small cell lung cancer (NSCLC), is the most common primary malignancy that metastasizes to the brain [1]. In several prospective and retrospective studies, the overall incidence of brain metastases (BM) in patients with NSCLC was $10-40 \%$ [2-6]. The prevalence of BM in patients with stage IV disease at presentation is approximately $26 \%$ [7]. The prognosis with BM is poor, and the median overall survival (OS) is generally 12 months or less [8]. To date, according to our knowledge, no study has looked at the survival benefit from detecting asymptomatic brain metastases in patients with NSCLC stage IV at presentation.

There are multiple considerations for the treatment of patients with BM. Chemotherapy has a limited role because of a presumed lack of effectiveness due to its poor penetration of the blood-brain barrier [9]. For patients presenting with epidermal growth factor receptor (EGFR)-mutated or anaplastic lymphoma kinase (ALK)-rearranged NSCLC, targeted therapies have shown efficacy and antitumor activity in the central nervous system (CNS) [10,11]. Additionally, emerging clinical data suggest that systemic immunotherapy monotherapy has activity in untreated BM from NSCLC with response rates around $30 \%$ [12-15]. Neurosurgery involves significant perioperative risks, and cranial irradiation is associated with toxicities, such as cognitive decline, radiation necrosis and cerebrovas- 
cular complications [16-21]. In the context of advanced disease, the objective of these treatments is palliation of symptoms.

In NSCLC, there are some discrepancies in practice guidelines over routine brain imaging for patients with advanced disease. The rationale behind routine neuroimaging in patients with stage IV disease would be early detection of brain metastases so that early treatment can be administered before development of neurologic deficits or seizures. Another possible benefit would be to treat less numerous and smaller lesions with stereotactic radiosurgery (SRS) and to avoid whole brain radiation therapy (WBRT). According to the American College of Chest Physicians (CHEST), brain imaging should be performed routinely on patients with stage III or IV disease, even if they do not have neurological symptoms [22]. The National Comprehensive Cancer Network (NCCN) also recommends that asymptomatic patients with stage IB or higher should undergo brain imaging [23]. The European Society of Medical Oncology (ESMO) claims that brain imaging should be reserved for patients with neurological symptoms [24]. In 2014, the Institut national d'excellence en santé et en services sociaux (INESSS) and the Groupe d'étude en oncologie du Québec (GEOQ) published algorithms for the investigation, treatment and monitoring of lung cancer. According to this document based on the opinion of fifty expert oncologists, a systematic investigation of asymptomatic brain metastases is recommended for stage III or higher [25]. The majority of practice guidelines advocate the use of magnetic resonance imaging (MRI) over computed tomography (CT) [22-25].

Given the lack of consensus in current practice guidelines, this study reports the proportion of patients with stage IV NSCLC without neurological symptoms undergoing brain imaging in their initial investigation, and survival outcomes according to initial cerebral imaging being performed or not.

\section{Materials and Methods}

\subsection{Study Design}

This retrospective study included all patients with stage IV NSCLC diagnosed between 1 January 2013 and 31 December 2016 at Institut universitaire de cardiologie et de pneumologie de Québec (IUCPQ). Patients were identified from the Oncology Database (SICTO). Patients with neurological symptoms at initial presentation were excluded.

\subsection{Data Collection}

Demographic data collected for this study included age, gender, smoking status and Eastern Cooperative Oncology Group performance status (ECOG PS). The medical charts were also reviewed for histopathological diagnosis, date of diagnosis, sites of metastases, use of a systemic treatment, EGFR, ALK and PD-L1 status. If brain imaging was performed initially at diagnosis or later in the course of the disease, the modality of imaging and the description of brain metastases were noted. Outcomes of patients were noted, mainly regarding the treatment modality offered for brain metastases, the onset of neurological symptoms or new/progressive brain metastases, and the date of death or last follow-up.

The primary outcome of this study was to compare the evolution of patients with stage IV NSCLC without neurological symptoms at diagnosis who had initial brain imaging with those who did not. Secondary outcomes were to determine the proportion of patients who underwent brain imaging in their initial investigation and the proportion of patients who developed metachronous CNS metastasis. The impact of mutational status on the presence of cerebral metastases and the course of the disease was also analyzed as a secondary objective.

\subsection{Statistical Analysis}

Patient demographics and clinical characteristics were summarized using descriptive methods. Continuous variables were reported as mean \pm standard deviation (SD) and analyzed using Student's $t$-test. Nominal variables were reported as frequencies and analyzed using the Fisher's exact tests for comparisons between groups. For the OS of 
patients with and without imaging, the Kaplan-Meier estimates and the log-rank test for between-group comparisons were performed. A Gray's test was used to account for death as a competing risk event for patients having metachronous CNS metastasis. For all statistical analyses, the results were considered significant with $p$-values $<0.05$. Analyses were performed using SAS version 9.4 (SAS Institute Inc., Cary, North Carolina) and $\mathrm{R}$ package.

\section{Results}

\subsection{Patients}

Four hundred and seventy-four patients diagnosed with stage IV non-small cell lung cancer were identified from the Oncology Database (SICTO) between 1 January 2013 and 31 December 2016. Patients with neurologic symptoms at diagnosis $(n=116)$ were excluded. Furthermore, 74 patients were diagnosed at our center but were transferred back to their referring institution for treatment and lost to follow-up. Hence, these patients were excluded due to missing data. Twenty-seven patients were excluded for other various reasons, and, finally, 257 patients were included in the analysis (Figure 1).

\section{4 patients with an initial diagnosis of stage IV NSCLC} between January 1, 2013 and December 31, 2016

Exclusion criteria :

- Neurologic symptoms at diagnosis $(n=116)$;

- Inconclusive imaging for the presence of brain

metastases $(n=6)$;

- Incomplete file $(n=74)$;

- Histopathological diagnosis other than NSCLC $(n=2)$;

- Another active cancer $(n=4)$;

- Brain imaging prescribed for a reason other than lung

cancer or neurological symptoms $(n=1)$;

- Stage I-II-III NSCLC $(n=14)$.

\section{7 patients included in the analysis}

Figure 1. Consort diagram. NSCLC = non-small cell lung cancer.

\subsection{Brain Imaging}

Baseline characteristics of all patients are summarized in Table 1. The population was divided in two groups, with 145 patients who underwent initial CNS imaging and 112 patients who did not. Patients with initial imaging were younger than those without (median age 65.1 vs. $68.5, p=0.0025)$. Most patients in both groups were male $(56 \%)$, former or current smokers (95\%) and had adenocarcinoma (73\%). ECOG PS was often missing from the charts. EGFR and $A L K$ alterations were uncommon ( $7 \%$ and $1 \%$, respectively). 
Bones were the most common site of metastases, involved in $54 \%$ of subjects with CNS imaging versus $67 \%$ of those without $(p=0.04)$.

Table 1. Patient characteristics.

\begin{tabular}{|c|c|c|c|c|}
\hline & All Patients & $\begin{array}{l}\text { Patients Who Underwent } \\
\text { Initial CNS Imaging }\end{array}$ & $\begin{array}{c}\text { Patients Who Did Not } \\
\text { Underwent Initial CNS Imaging }\end{array}$ & \multirow[t]{2}{*}{$p$-Value } \\
\hline & $n=257$ & $n=145$ & $n=112$ & \\
\hline Median age, years \pm SD & $66.6 \pm 9.2$ & $65.1 \pm 9.5$ & $68.5 \pm 8.4$ & 0.0025 \\
\hline Male sex & $144(56 \%)$ & $76(52 \%)$ & $68(61 \%)$ & 0.2059 \\
\hline Former or current smoker & $244(95 \%)$ & $140(97 \%)$ & $104(93 \%)$ & 0.2514 \\
\hline \multicolumn{5}{|l|}{ ECOG PS } \\
\hline $0-1$ & $70(27 \%)$ & $41(28 \%)$ & $29(26 \%)$ & \multirow{3}{*}{0.5612} \\
\hline$\geq 2$ & $40(16 \%)$ & $25(17 \%)$ & $15(13 \%)$ & \\
\hline Not reported & $147(57 \%)$ & $79(55 \%)$ & $68(61 \%)$ & \\
\hline \multicolumn{5}{|l|}{ Histology } \\
\hline Adenocarcinoma & $187(73 \%)$ & $106(73 \%)$ & $81(72 \%)$ & \multirow{5}{*}{0.6169} \\
\hline Squamous carcinoma & $44(17 \%)$ & $25(17 \%)$ & $19(17 \%)$ & \\
\hline $\begin{array}{l}\text { Adenosquamous } \\
\text { carcinoma }\end{array}$ & $5(2 \%)$ & $4(3 \%)$ & $1(1 \%)$ & \\
\hline Large cell carcinoma & $1(0 \%)$ & $1(1 \%)$ & 0 & \\
\hline NSCLC NOS & $20(8 \%)$ & $9(6 \%)$ & $11(10 \%)$ & \\
\hline \multicolumn{5}{|l|}{ EGFR mutation } \\
\hline Positive & $17(7 \%)$ & $11(8 \%)$ & $6(5 \%)$ & \multirow{5}{*}{0.8239} \\
\hline Negative & $153(59 \%)$ & $85(59 \%)$ & $68(61 \%)$ & \\
\hline $\begin{array}{l}\text { Not tested (squamous } \\
\text { carcinoma) }\end{array}$ & $43(17 \%$ & $25(17 \%)$ & $18(16 \%)$ & \\
\hline Not tested (ALK-positive) & $3(1 \%)$ & $3(2 \%)$ & 0 & \\
\hline Unknown* & $41(16 \%)$ & $21(14 \%)$ & $20(18 \%)$ & \\
\hline \multicolumn{5}{|l|}{$A L K$ rearrangement } \\
\hline Positive & $3(1 \%)$ & $3(2 \%)$ & 0 & \multirow{4}{*}{0.3685} \\
\hline Negative & $171(66 \%)$ & $97(67 \%)$ & $74(66 \%)$ & \\
\hline $\begin{array}{l}\text { Not tested (squamous } \\
\text { carcinoma) }\end{array}$ & $43(17 \%)$ & $25(17 \%)$ & $18(16 \%)$ & \\
\hline Unknown * & $40(16 \%)$ & $20(14 \%)$ & $20(18 \%)$ & \\
\hline \multicolumn{5}{|l|}{ PD-L1 status } \\
\hline$<1 \%$ & $6(2 \%)$ & $5(4 \%)$ & $1(1 \%)$ & \multirow{4}{*}{0.5636} \\
\hline $1-49 \%$ & $7(3 \%)$ & $3(2 \%)$ & $4(4 \%)$ & \\
\hline$\geq 50 \%$ & $12(5 \%)$ & $7(5 \%)$ & $5(5 \%)$ & \\
\hline Unknown ** & $232(90 \%)$ & $130(90 \%)$ & $102(91 \%)$ & \\
\hline \multicolumn{5}{|l|}{ T stage } \\
\hline 1 & $28(11 \%)$ & $14(10 \%)$ & $14(13 \%)$ & \multirow{5}{*}{0.2783} \\
\hline 2 & $53(21 \%)$ & $31(21 \%)$ & $22(20 \%)$ & \\
\hline 3 & $61(24 \%)$ & $33(23 \%)$ & $28(25 \%)$ & \\
\hline 4 & $94(37 \%)$ & $59(41 \%)$ & $35(31 \%)$ & \\
\hline $\mathrm{x}$ & $21(8 \%)$ & $8(6 \%)$ & $13(12 \%)$ & \\
\hline
\end{tabular}


Table 1. Cont.

\begin{tabular}{|c|c|c|c|c|}
\hline & All Patients & $\begin{array}{l}\text { Patients Who Underwent } \\
\text { Initial CNS Imaging }\end{array}$ & $\begin{array}{c}\text { Patients Who Did Not } \\
\text { Underwent Initial CNS Imaging }\end{array}$ & \multirow[t]{2}{*}{$p$-Value } \\
\hline & $n=257$ & $n=145$ & $n=112$ & \\
\hline \multicolumn{5}{|l|}{ N stage } \\
\hline 0 & $28(11 \%)$ & $15(10 \%)$ & $13(12 \%)$ & \multirow{5}{*}{0.1104} \\
\hline 1 & $20(8 \%)$ & $13(9 \%)$ & $7(6 \%)$ & \\
\hline 2 & $97(38 \%)$ & $46(32 \%)$ & $51(46 \%)$ & \\
\hline 3 & $105(41 \%)$ & $68(47 \%)$ & $37(33 \%)$ & \\
\hline$x$ & $7(3 \%)$ & $3(2 \%)$ & $4(4 \%)$ & \\
\hline \multicolumn{5}{|c|}{$\begin{array}{c}\text { Sites of metastases at } \\
\text { diagnosis }\end{array}$} \\
\hline CNS & $47(18 \%)$ & $47(32 \%)$ & & \\
\hline Lung & $54(21 \%)$ & $30(21 \%)$ & $24(21 \%)$ & 0.8788 \\
\hline Pleura & $37(14 \%)$ & $18(12 \%)$ & 19 (17\%) & 0.3707 \\
\hline Liver & $69(27 \%)$ & $34(24 \%)$ & $35(31 \%)$ & 0.2013 \\
\hline Bone & $153(59 \%)$ & $78(54 \%)$ & $75(67 \%)$ & 0.0403 \\
\hline Adrenal & $61(24 \%)$ & $30(21 \%)$ & $31(38 \%)$ & 0.2369 \\
\hline \multicolumn{5}{|c|}{ CNS imaging modality } \\
\hline $\mathrm{CT}$ & & $112(77 \%)$ & & \\
\hline MRI & & $18(12 \%)$ & & \\
\hline Both & & $15(10 \%)$ & & \\
\hline
\end{tabular}

ALK = Anaplastic lymphoma kinase; CNS = central nervous system; CT = computed tomography; ECOG PS = Eastern Cooperative Oncology Group performance status; EGFR = epidermal growth factor receptor; MRI = magnetic resonance imaging; NOS = not otherwise specified; NSCLC = non-small cell lung cancer; $\mathrm{SD}=$ standard deviation. * Testing was not performed for 40 patients for various reasons: poor performance status precluding systemic treatment $(n=27)$, treatment refusal by patient $(n=5)$, lack of tissue $(n=4)$ and no reason documented in the medical chart $(n=4)$. Additionally, one patient had an ALK-negative tumor but insufficient tissue for EGFR testing. ** PD-L1 status is unknown in the majority of cases since immune checkpoint inhibitors were not readily available at this time.

Among patients undergoing brain imaging, 112/145 (77\%) patients had a CT scan, while MRI alone was chosen only in 18/145 (12\%), and both imaging techniques were used in $15 / 145(10 \%)$. CNS metastases were diagnosed in $47 / 145$ patients $(32 \%)$ with initial imaging (synchronous metastasis). Of these, 26/47 (55\%) received systemic treatment. There was no difference in the proportion of patients receiving systemic therapy in the group with negative imaging $(55 / 98,56 \%)$ versus in the group without imaging $(57 / 112,51 \%)$.

\subsection{Brain Metastasis}

Among patients with synchronous CNS metastasis, 18/47 (38\%) had a single brain lesion and $11 / 47(24 \%)$ had $\geq 5$ (Table 2). Synchronous metastases were treated by WBRT in $25 / 47(53 \%)$ patients, by SRS in $9 / 47(19 \%)$ and by SRS and WBRT in $1 / 47(2 \%)$, while $12 / 47(26 \%)$ were not treated. Metachronous metastasis was diagnosed in 32 patients, including 13 patients with synchronous metastasis, 5 patients with initial negative imaging, and 14 patients without initial imaging (Figure 2). Only $5 / 32$ were a single metachronous CNS metastasis. The majority of patients $(28 / 32,88 \%)$ were symptomatic. Metachronous metastases were treated by WBRT in $12 / 32(38 \%)$ patients, by SRS in $5 / 32(16 \%)$ and by surgery in $2 / 32(6 \%)$, while $13 / 32(41 \%)$ were not treated.

CNS imaging was performed at diagnosis in $11 / 17(65 \%)$ patients with EGFR-mutated and in $3 / 3(100 \%)$ with $A L K$-rearranged NSCLC. Synchronous CNS metastases were diagnosed in $1 / 17(6 \%)$ and $2 / 3(67 \%)$, respectively. These patients all received systemic therapy and underwent WBRT. EGFR-mutated and ALK-rearranged NSCLC were found to have metachronous CNS metastases in 4/17 (24\%) and 1/3 (33\%) of cases, and they were all symptomatic (Figures S1 and S2). 
According to Figure 3, the cumulative incidence of metachronous CNS metastases tended to be lower in patients with initial imaging compared to patients without, but the difference between the two groups was not significant $(p=0.06)$. The 3-year cumulative incidence of brain metastases was 5.1\% (95\% confidence interval [CI] 1.9-10.8\%) in patients with initial CNS imaging versus $12.5 \%$ (95\% CI 7.1-19.4\%) in patients without. Median OS was similar between the two groups; 5.9 months $(95 \%$ CI $4.0-7.8)$ in patients with initial brain imaging and 5.8 months (95\% CI 4.1-7.1) in patients without (Figure 4A, $p=0.32$ ). According to Figure 4B, OS of patients who received systemic treatment was improved regardless of if initial brain imaging was performed or not $(p<0.001$ for the comparison of patients who received systemic treatment versus patients who did not). There was no difference in the time from diagnosis of CNS metastases to death in patients with synchronous versus de novo metachronous metastases (Figure $5, p=0.48$ ).

Table 2. CNS metastasis.

\begin{tabular}{|c|c|c|c|c|c|}
\hline & \multirow[b]{2}{*}{$\begin{array}{c}\text { Synchronous CNS } \\
\text { Metastasis }\end{array}$} & \multicolumn{3}{|c|}{ Metachronous CNS Metastasis } & \multirow{3}{*}{$p$-Value * } \\
\hline & & $\begin{array}{c}\text { With CNS } \\
\text { Metastasis at Initial } \\
\text { Imaging * }\end{array}$ & $\begin{array}{c}\text { Without CNS } \\
\text { Metastasis at Initial } \\
\text { Imaging }\end{array}$ & $\begin{array}{l}\text { Without Initial } \\
\text { Imaging }\end{array}$ & \\
\hline & $n=47$ & $n=13$ & $n=5$ & $n=14$ & \\
\hline \multicolumn{6}{|l|}{$\begin{array}{l}\text { Number of } \\
\text { metastases }\end{array}$} \\
\hline 1 & $18(38 \%)$ & $2(15 \%)$ & $2(40 \%)$ & $1(7 \%)$ & \multirow{3}{*}{0.1024} \\
\hline $2-4$ & $18(38 \%)$ & $5(39 \%)$ & 0 & $8(57 \%)$ & \\
\hline$\geq 5$ & $11(23 \%)$ & $6(46 \%)$ & $3(60 \%)$ & $5(36 \%)$ & \\
\hline \multicolumn{6}{|l|}{ Symptoms } \\
\hline None & $47(100 \%)$ & $4(31 \%)$ & 0 & 0 & \multirow{4}{*}{$<0.0001$} \\
\hline Headache & & $3(23 \%)$ & 0 & $3(21 \%)$ & \\
\hline $\begin{array}{l}\text { Neurological } \\
\text { impairement }\end{array}$ & & $4(31 \%)$ & $5(100 \%)$ & $11(79 \%)$ & \\
\hline Seizure & & $2(15 \%)$ & 0 & 0 & \\
\hline \multicolumn{6}{|l|}{ Treatment } \\
\hline None & $12(26 \%)$ & $4(31 \%)$ & $2(40 \%)$ & $7(50 \%)$ & \multirow{5}{*}{0.5704} \\
\hline WBRT & $25(53 \%)$ & $4(31 \%)$ & $2(40 \%)$ & $6(43 \%)$ & \\
\hline SRS & $9(19 \%)$ & $3(23 \%)$ & $1(20 \%)$ & $1(7 \%)$ & \\
\hline SRS + WBRT & $1(2 \%)$ & 0 & 0 & 0 & \\
\hline Surgery & 0 & $2(15 \%)$ & 0 & 0 & \\
\hline
\end{tabular}

CNS = central nervous system; SRS = stereotactic radiosurgery; WBRT = whole brain radiotherapy. ${ }^{*}$ The $p$-values do not apply for patients with metachronous CNS metastasis who already had CNS metastasis at initial imaging $(n=13)$. 


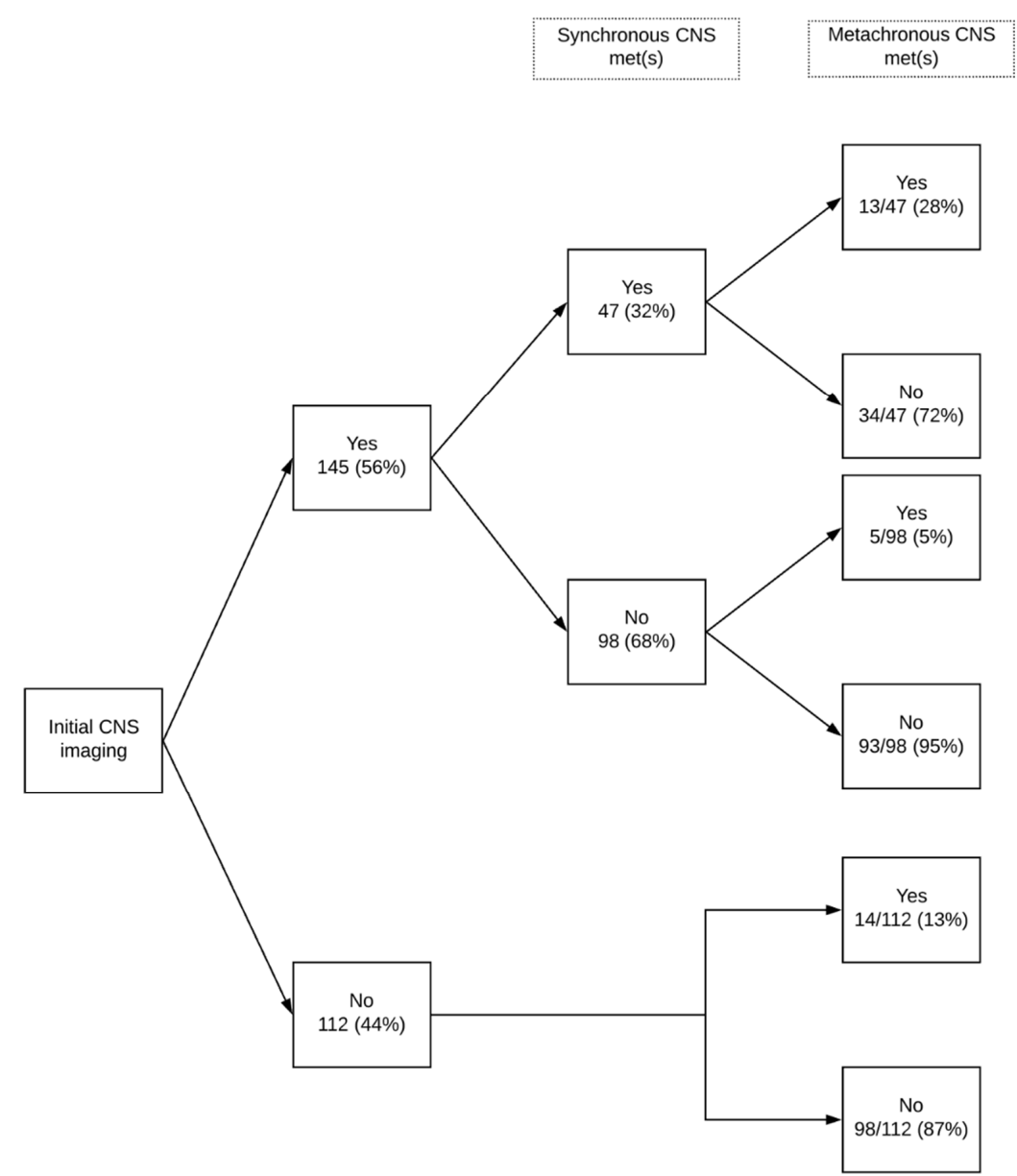

Figure 2. Synchronous and metachronous CNS metastases. CNS = central nervous system; met = metastasis.

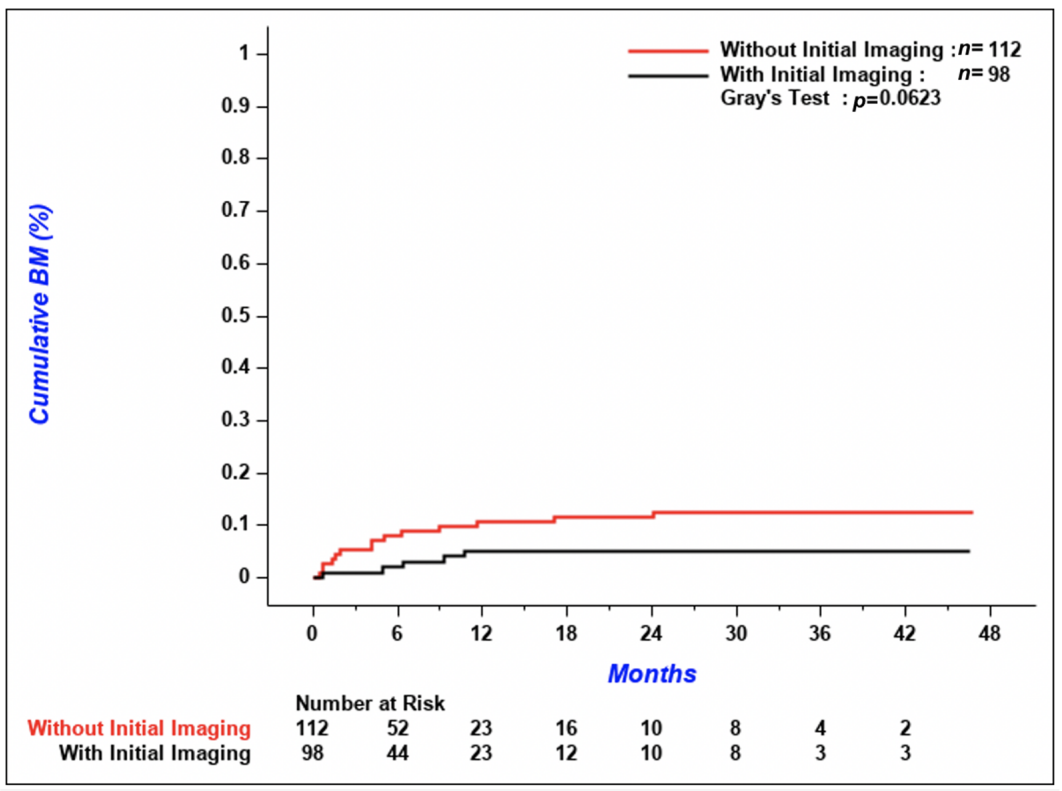

Figure 3. Cumulative incidence of metachronous brain metastases. $\mathrm{BM}=$ brain metastases. 

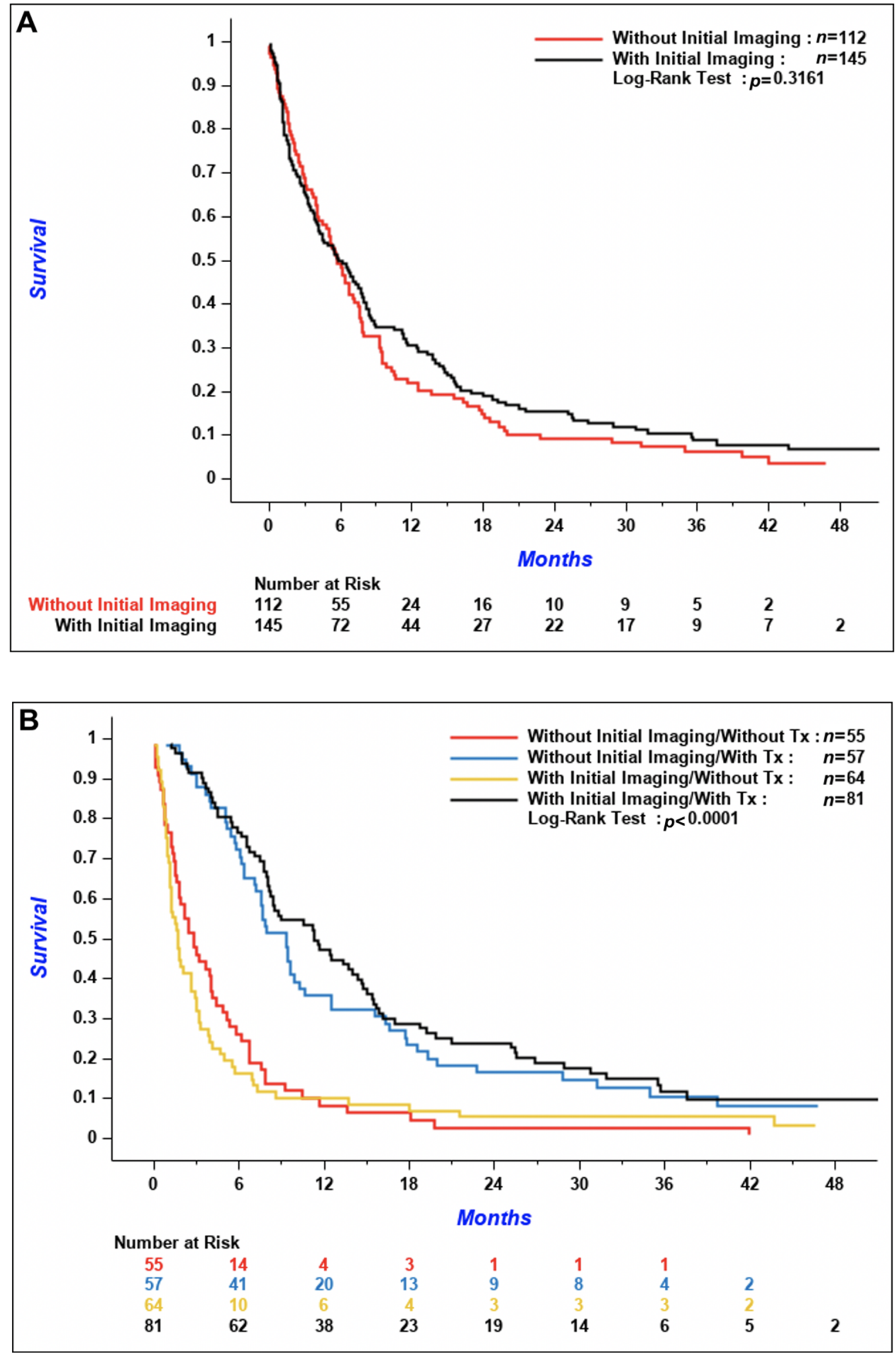

Figure 4. (A) Overall survival of patients with initial brain imaging versus patients without initial imaging. (B) Overall survival of patients with initial brain imaging versus patients without initial imaging, stratified by systemic treatment. 


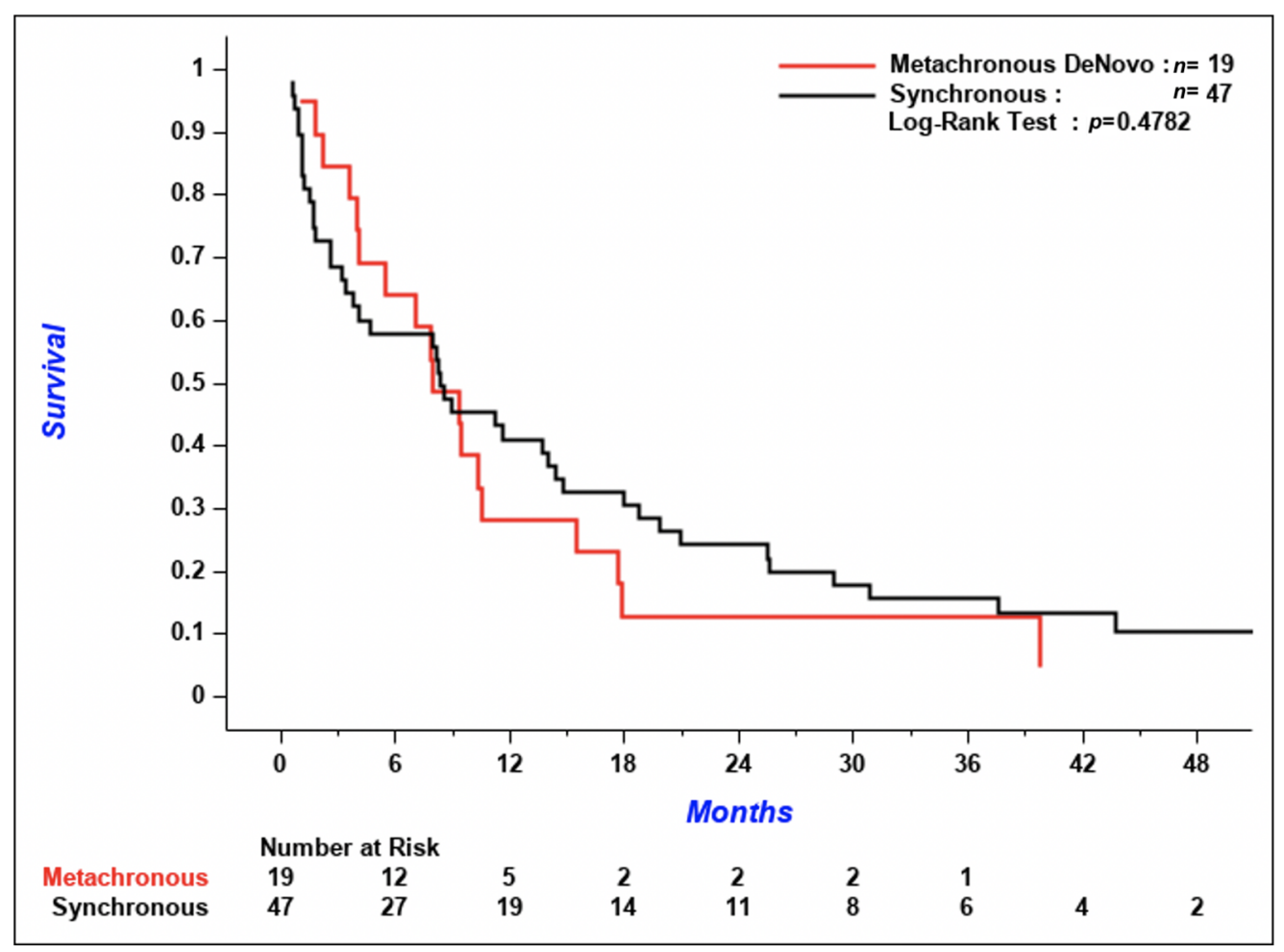

Figure 5. Time from diagnosis of CNS metastases to death in patients with synchronous CNS metastases versus de novo metachronous CNS metastases. CNS = central nervous system.

\section{Discussion}

In this monocentric cohort of stage IV NSCLC patients without neurologic symptoms, CNS imaging, mainly with CT alone (77\%), was performed at diagnosis in $56 \%$ of patients, and the prevalence of synchronous CNS metastasis among these patients was $32 \%$. During the follow-up of the 257 patients in the entire cohort, 32 developed BM (metachronous metastasis). Among these 32 patients, 13 of them already had brain metastases initially. The prevalence of CNS metastases at any time during disease course in the whole cohort was $26 \%$. We did not demonstrate a difference in median OS between patients who underwent initial CNS imaging and those who did not. OS of patients who received systemic treatment was improved regardless of if initial brain imaging was performed or not. However, we did show a tendency for a higher cumulative incidence of metachronous CNS metastasis in patients without baseline imaging, but the $p$-value was not statistically significant $(p=0.06)$. These metachronous metastases were symptomatic and were more often not treated when compared to synchronous metastases. However, there was no difference in the time from diagnosis of CNS metastases to death in patients with synchronous versus de novo metachronous metastases. The prevalence of patients with EGFR-mutated and ALKrearranged NSCLC in our cohort was low, so we were not able to draw any conclusions on the impact of these biomarkers on the prevalence and incidence of brain metastases and on the course of the disease.

The question of our study is relevant. For patients without neurological symptoms, it is interesting to wonder if initial brain imaging changes the course of a disease already advanced at diagnosis. It must be established whether there is a survival benefit in diagnosing asymptomatic cerebral metastases in patients who already have a poor prognosis. The study design seems adequate to answer this question.

Regarding patient characteristics, the study sample still represents the usual population of patients with stage IV NSCLC. Median age of the patients was 67 years; they were predominantly male and former or current smokers. The majority had a histopathological diagnosis of adenocarcinoma, with a large tumor, multiple lymphadenopathies and ex- 
trathoracic metastases. The proportion of patients who have received systemic treatment and local therapies for brain metastases roughly reflects what is usually seen in practice.

\section{Limitations}

Our results are limited by the retrospective nature of the study, by a small sample and by the fact that the study is unicentric. Several patients were excluded from the study because they had neurologic symptoms or were lost to follow-up. In addition, we clearly did not include enough patients with ALK-rearranged and EGFR-mutated NSCLC ( $n=$ 3 and 17 respectively) to assess the impact of these mutations on the presence of brain metastases and the course of their disease. This is partially explained by the fact that these mutations were not always routinely tested between 2013 and 2016, but also because our population in Quebec City is mainly composed of Caucasians and heavy smokers. Additionally, newer generation tyrosine kinase inhibitors (TKIs) were not available at that time, which might explain why baseline neuroimaging was not always performed in this population, and the high proportion of these patients undergoing WBRT, which is clearly not the treatment of choice in 2020. Given the retrospective nature of the study, some information were missing or poorly described, such as ECOG PS and symptoms. Furthermore, since the field of pulmonary oncology has evolved very quickly, it is unlikely that the trends described in this study can be transposed to the past few years.

\section{Conclusions}

In this retrospective cohort of patients with stage IV NSCLC without neurologic symptoms, there was no significant difference in terms of survival in the group who underwent initial brain imaging compared to the group who did not. OS of patients seemed to be influenced more by systemic treatment rather than initial brain imaging. However, the cumulative incidence of metachronous brain metastasis tended to be lower in patients with initial brain imaging.

More studies are needed to assess the effects on various outcomes (incidence of metachronous CNS metastases, development of symptoms, choice of local or systemic treatments, median OS) of routine neuroimaging in asymptomatic patients with stage IV NSCLC, with ideally prospective cohorts who have access to contemporary treatments, including immunotherapy, newer generation TKIs and SRS. We still believe there is a rationale for early detection of brain metastases so that early treatment can be administered before the development of neurologic deficits or seizures.

Supplementary Materials: The following are available online at https:/ / www.mdpi.com/1718-772 9/28/2/108/s1, Figure S1: Synchronous and metachronous CNS metastases (EGFR-mutated NSCLC), Figure S2: Synchronous and metachronous CNS metastases (ALK-rearranged NSCLC).

Author Contributions: Conceptualization, M.D.P. and C.L.; methodology, M.D.P. and C.L.; software, M.D.P. and C.L.; validation, M.D.P. and C.L.; formal analysis, M.D.P. and C.L.; investigation, M.D.P. and C.L.; resources, M.D.P. and C.L.; data curation, M.D.P.; writing-original draft preparation, M.D.P. and C.L.; writing-review and editing, M.D.P. and C.L.; visualization, M.D.P. and C.L.; supervision, C.L.; project administration, M.D.P. and C.L.; funding acquisition, not applicable. All authors have read and agreed to the published version of the manuscript.

Funding: This research received no external funding.

Institutional Review Board Statement: The study was conducted according to the guidelines of the Declaration of Helsinki, and approved by the Institutional Review Board (or Ethics Committee) of Institut Universitaire de Cardiologie et de Pneumologie de Québec (protocol code 2019-3089, 21656, on 20 July 2018).

Informed Consent Statement: Patient consent was waived due to the fact that it was a retrospective chart review with no impact on patients. Moreover, the majority of patients had died at the time of analysis. 
Data Availability Statement: The data presented in this study are available on request from the corresponding author.

Acknowledgments: The authors acknowledge Serge Simard, from the Centre de recherche de l'Institut universitaire de cardiologie et de pneumologie de Québec, Université Laval, Québec, for statistical analyses.

Conflicts of Interest: The authors declare no conflict of interest.

\section{References}

1. Singh, R.; Stoltzfus, K.C.; Chen, H.; Louie, A.V.; Lehrer, E.J.; Horn, S.R.; Palmer, J.D.; Trifiletti, D.M.; Brown, P.D.; Zaorsky, N.G. Epidemiology of synchronous brain metastases. Neurooncol Adv. 2020, 2, vdaa041. [CrossRef]

2. Nayak, L.; Lee, E.Q.; Wen, P.Y. Epidemiology of Brain Metastases. Curr. Oncol. Rep. 2012, 14, 48-54. [CrossRef]

3. Shi, A.A.; Digumarthy, S.R.; Temel, J.S.; Halpern, E.F.; Kuester, L.B.; Aquino, S.L. Does initial staging or tumor histology better identify asymptomatic brain metastases in patients with non-small cell lung cancer? J. Thorac. Oncol. 2006, 1, 205-210. [CrossRef]

4. Sørensen, J.B.; Hansen, H.H.; Hansen, M.; Dombernowsky, P. Brain metastases in adenocarcinoma of the lung: Frequency, risk groups, and prognosis. J. Clin. Oncol. 1988, 6, 1474-1480. [CrossRef]

5. Patchell, R.A. The management of brain metastases. Cancer Treat. Rev. 2003, 29, 33-540. [CrossRef]

6. Cagney, D.N.; Martin, A.M.; Catalano, P.J.; Redig, A.J.; Lin, N.U.; Lee, E.Q.; Wen, P.Y.; Dunn, I.F.; Bi, W.L.; Weiss, S.E.; et al. Incidence and prognosis of patients with brain metastases at diagnosis of systemic malignancy: A population-based study. Neuro Oncol. 2017, 19, 1511-1521. [CrossRef] [PubMed]

7. Waqar, S.N.; Samson, P.P.; Robinson, C.G.; Bradley, J.; Devarakonda, S.; Du, L.; Govindan, R.; Gao, F.; Puri, V.; Morgensztern, D. Non-small-cell Lung Cancer with Brain Metastasis at Presentation. Clin. Lung Cancer 2018, 19, e373-e379. [CrossRef] [PubMed]

8. Sperduto, P.W.; Yang, T.J.; Beal, K.; Pan, H.; Brown, P.D.; Bangdiwala, A.; Shanley, R.; Yeh, N.; Gaspar, L.E.; Braunstein, S.; et al. Estimating Survival in Patients with Lung Cancer and Brain Metastases: An Update of the Graded Prognostic Assessment for Lung Cancer Using Molecular Markers (Lung-molGPA). JAMA Oncol. 2017, 3, 827-831. [CrossRef] [PubMed]

9. Schuette, W. Treatment of brain metastases from lung cancer: Chemotherapy. Lung Cancer 2004, 45 (Suppl. 2), S253. [CrossRef] [PubMed]

10. Ballard, P.; Yates, J.W.; Yang, Z.; Kim, D.W.; Yang, J.C.; Cantarini, M.; Pickup, K.; Jordan, A.; Hickey, M.; Grist, M.; et al. Preclinical Comparison of Osimertinib with Other EGFR-TKIs in EGFR-Mutant NSCLC Brain Metastases Models, and Early Evidence of Clinical Brain Metastases Activity. Clin. Cancer Res. 2016, 22, 5130-5140. [CrossRef] [PubMed]

11. Griesinger, F.; Roeper, J.; Pöttgen, C.; Willborn, K.C.; Eberhardt, W.E.E. Brain metastases in ALK-positive NSCLC—Time to adjust current treatment algorithms. Oncotarget 2018, 9, 35181-35194. [CrossRef] [PubMed]

12. Goldberg, S.B.; Schalper, K.A.; Gettinger, S.N.; Mahajan, A.; Herbst, R.S.; Chiang, A.C.; Lilenbaum, R.; Wilson, F.H.; Omay, S.B.; Yu, J.B.; et al. Pembrolizumab for management of patients with NSCLC and brain metastases: Long-term results and biomarker analysis from a non-randomised, open-label, phase 2 trial. Lancet Oncol. 2020, 21, 655-663. [CrossRef]

13. Yang, K.; Li, J.; Bai, C.; Sun, Z.; Zhao, L. Efficacy of Immune Checkpoint Inhibitors in Non-small-cell Lung Cancer Patients with Different Metastatic Sites: A Systematic Review and Meta-Analysis. Front. Oncol. 2020, 10, 1098. [CrossRef] [PubMed]

14. Majd, N.; Dasgupta, P.; de Groot, J. Immunotherapy for Neuro-Oncology. Adv. Exp. Med. Biol. 2020, 1244, $183-203$.

15. Wang, S.; Hu, C.; Xie, F.; Liu, Y. Use of Programmed Death Receptor-1 and/or Programmed Death Ligand 1 Inhibitors for the Treatment of Brain Metastasis of Lung Cancer. Oncol. Targets Ther. 2020, 13, 667-683. [CrossRef] [PubMed]

16. Day, J.; Zienius, K.; Gehring, K.; Grosshans, D.; Taphoorn, M.; Grant, R.; Li, J.; Brown, P.D. Interventions for preventing and ameliorating cognitive deficits in adults treated with cranial irradiation. Cochrane Database Syst. Rev. 2014, CD011335. [CrossRef]

17. Sheline, G.E.; Wara, W.M.; Smith, V. Therapeutic irradiation and brain injury. Int. J. Radiat. Oncol. Biol. Phys. 1980, 6, 1215-1228. [CrossRef]

18. Lamba, N.; Muskens, I.S.; DiRisio, A.C.; Meijer, L.; Briceno, V.; Edrees, H.; Aslam, B.; Minhas, S.; Verhoeff, J.J.; Kleynen, C.E.; et al. Stereotactic radiosurgery versus whole-brain radiotherapy after intracranial metastasis resection: A systematic review and meta-analysis. Radiat. Oncol. 2017, 12, 106. [CrossRef]

19. Blonigen, B.J.; Steinmetz, R.D.; Levin, L.; Lamba, M.A.; Warnick, R.E.; Breneman, J.C. Irradiated volume as a predictor of brain radionecrosis after linear accelerator stereotactic radiosurgery. Int. J. Radiat. Oncol. Biol. Phys. 2010, 77, 996-1001. [CrossRef] [PubMed]

20. Minniti, G.; Clarke, E.; Lanzetta, G.; Osti, M.F.; Trasimeni, G.; Bozzao, A.; Romano, A.; Enrici, R.M. Stereotactic radiosurgery for brain metastases: Analysis of outcome and risk of brain radionecrosis. Radiat Oncol. 2011, 6, 48. [CrossRef] [PubMed]

21. Murphy, E.S.; Xie, H.; Merchant, T.E.; Jennifer, S.Y.; Chao, S.T.; Suh, J.H. Review of cranial radiotherapy-induced vasculopathy. J. Neurooncol. 2015, 122, 421-429. [CrossRef] [PubMed]

22. Silvestri, G.A.; Gonzalez, A.V.; Jantz, M.A.; Margolis, M.L.; Gould, M.K.; Tanoue, L.T.; Harris, L.J.; Detterbeck, F.C. Methods for staging non-small cell lung cancer: Diagnosis and management of lung cancer, 3rd ed: American College of Chest Physicians evidence-based clinical practice guidelines. Chest 2013, 143 (Suppl. 5), e211S-e250S. [CrossRef]

23. National Comprehensive Cancer Network. NCCN Clinical Practive Guidelines: Non-Small Cell Lung Cancer. Version 4.2018. 212p. Available online: https:/ /www.nccn.org/professionals/physician_gls/pdf/nscl.pdf (accessed on 25 June 2018). 
24. Reck, M.; Popat, S.; Reinmuth, N.; De Ruysscher, D.; Kerr, K.M.; Peters, S. Metastatic non-small-cell lung cancer (NSCLC): ESMO Clinical Practice Guidelines for diagnosis, treatment and follow-up. Ann. Oncol. 2016, 27 (Suppl. 5), v1-v27. [CrossRef] [PubMed]

25. Institut National D'excellence en Santé et en Services Sociaux (INESSS); Groupe D'étude en Oncologie du Québec (GEOQ). Algorithmes D'investigation, de Traitement et de Suivi Cancer du Poumon; par Gino Boily, Jim Boulanger, Stéphanie Goulet et Marie-Christine Paquin; INESSS: Québec City, QC, USA; GEOQ: Québec City, QC, USA, 2014; 269p. 